\title{
RATIONAL CHOICE THEORY AND DEMAND FOR PETTY CORRUPTION
}

\author{
Javlon Juraev \\ Norwegian Institute of International Affairs (NUPI)
}

\begin{abstract}
This article studies corruption as a rational choice phenomenon. Unlike the widespread game-theory approach to explaining corrupt behaviour, this article attempts to describe corruption as continuous utility-maximizing problem. It comes up with a demand for corruption function, which shows how the readiness of a rational person to accept corrupt income depends on several factors such as official wage rate, severity of punishment, awareness of those penalties, probability of being detected and probability of being prosecuted.
\end{abstract}

Keywords: Petty corruption, Rational choice theory, Economic modelling.

DOI: http://dx.doi.org/10.15549/jeecar.v5i2.219

\section{INTRODUCTION}

People usually associate corruption with big money. However, there is a type of bribery, which takes place in small offices and with lesser amounts of money. This type of corruption - petty corruption as it is called does not make big news. Yet, its hazard for economic efficiency is no less dangerous than that of grand corruption.

This article attempts to explain the phenomenon of petty corruption from a demand point of view, i.e. we try to understand why public officers take small bribes. We start with a review of previous studies on corruption to formulate the theoretical framework for our study. We then build a 'demand for petty corruption' model based on set of assumptions. We conclude our work with policy implications of the proposed model.

\section{THEORY OF CORRUPTION}

\section{Definition of Petty Corruption}

The first and foremost problem in studying corruption as an economic phenomenon arises from absence of commonly accepted solid definition of corruption (Nas, Price, \& Weber, 1986). Hence, we review different approaches to defining corruption and attempt to synthesize a more comprehensive working definition of corrupt behaviour. We start with close examination of three criteria for defining corruption suggested by Gardiner: legal, public interest and public opinion (Gardiner, 2009).

The legal criterion describes corruption as any act that is defined in statutes in force to be corrupt (Gardiner, 2009). This criterion follows a legislative philosophy of unambiguity - when law clearly says this or that is corrupt and punishable behaviour, people are expected to know and follow these rules.

The legal definition of corruption is bounded by several weaknesses. First, being based on a positivist approach, it neglects all economically 
distortive actions which are not defined in law. Second, this definition has a serious conflict of interest in its source: if the legislators define what is illegal, they may not base their judgement on common ethical norms, but on their personal views and norms of their social group. This is also true in the case of corruption.

The public interest approach states that any action which harms public interest in favour of personal benefit is corrupt (Gardiner, 2009). Compared to the legal definition, this one seems to be more 'just' or 'justified'. However, the public interest approach also suffers from weakness: in practice, it is impossible to objectively measure deviations from public interest.

The public opinion approach defines corruption as an action which is considered as corrupt by the majority (Gardiner, 2009). This approach concentrates on the opinion of the public about corrupt behaviour, ignoring the legal definition. As a result, a nation's legislation can set some actions to be corrupt, while the majority considers them tolerable and vice versa.

The problem with the public opinion based approach is that it creates serious inconsistency in defining corruption across nations. In some countries gift giving at the workplace is a cultural habit, while in others it is considered as unethical. Moreover, diverse groups of a population may have different views on a specific corrupt action. The more educated part of the society will have an opinion on the issues of corruption that is different from that of the less educated class. As a result, it is hard to come up with a clear-cut definition which would be commonly accepted.

The legal and public interest approaches to defining corruption are objective approaches, and the public opinion criteria - is a subjective one (Ndongmo, 2014). Among these three, we choose the public interest approach to work with, as it is an efficiency-based approach which makes it more suitable for economic analysis.

Many researchers accept a common basic definition of corruption which states that corruption "is the misuse of public office for private gain" (Svensson, 2015). Similar definitions that follow the public interest approach are used by Nas, Price and Weber (1986), and Rose-Ackerman (1978). The scope of the present article is limited to petty corruption: hence, further we focus on the definition of petty corruption. Ndongmo provides the following definition for this type of corruption:

"Petty corruption or bureaucratic corruption refers to corrupt practices involving public officers with low levels of authority." (Ndongmo, 2014, p. 28)

We develop this definition further to reflect previous discussions:

Petty corruption is practices which create distortions in public welfare and involve public officials with low levels of authority. As a rule, these practices take place on a regular basis and involve continuous flow of monetary bribes in small sums.

Three important moments in the proposed definition need further clarification. First, we state that petty corruption is an action of distortive nature for public interest. This ensures the objectivity of the approach to define a behaviour as corrupt. Second, we underline that petty corruption is a continuous (repetitive) process. This is a crucial point for our analysis, as it postulates that petty corruption is not a one-time game case. A person decides how much bribe he is ready to accept continuously throughout a certain period. And finally, this type of corruption involves a small amount of money, which excludes cases of grand corruption, (where big money is involved and risks are much higher).

\section{Causes of corrupt Behaviour}

Previous studies underline the problem of identifying the causes of corruption. As Heywood points out, the complexity of corruption as a phenomenon makes it nearly impossible to adequately explain its causes (Heywood, 1997). We review six different approaches to explaining the causes of corruption outlined by de Graaf: public choice, 'bad apple', organizational culture, clashing moral values, public administration, and statistical correlation (De Graaf, 2007).

We divide these six approaches to explaining causes of corruption into two groups: reflective and expressive. The reflective approach says that corrupt behaviour is a reaction (or reflection) of a person to external influences. The expressive explanation, on the contrary, states that corrupt behaviour is a choice of an individual.

One example of the reflective explanation is the 'bad apple' theory, which states that the 
cause of corrupt behaviour is rooted in the faulty nature of some individuals (De Graaf, 2007). According to this theory, some people are educated with 'wrong' values and a lack of morality. These defects in character inevitably lead to criminal behaviour. This, however, does not explain the cases where well-educated people are involved in corruption. Blank spots like this make this theory weak in explaining corruption. Thus, we cannot accept it as reliable theory of all causes of corruption.

Another reflective explanation is the organizational culture theory, which states that corrupt behaviour of a person is a result of social (group) culture of an organization he is working in (De Graaf, 2007). Punch describes this theory with the example of a police officer, who - when subjected to corrupt organization culture - inevitably gets corrupted (Punch, 2000).

The third group of theories is the clashing values, which states that if a person's moral obligations to his close group (family and/or friends) prevail over his moral obligations towards broader society, he might choose to be corrupt (De Graaf, 2007). Here a moral conflict takes place, if there is a discrepancy between the interests of the close group and those of the public. We admit that family or community ties can be a strong factor (especially, in some cultures). Yet, we refrain from concluding that moral obligations towards a close circle of a person is a cause of corruption in every case. A corrupt person can use his ties to a briber to rationalize and justify his wrongdoing, but corrupt behaviour is a result of many factors.

Public administration theories are very similar to clashing values theories. They also fall under the reflective explanation category. As de Graaf explains it, social pressure on officials about their 'effectiveness' in combination with lack of attention to integrity issues ends in officials concentrating on their performance and becoming corrupt (De Graaf, 2007). Heywood, while comparing nations in Europe, argued that in political structures where businessmen are also involved in politics, there is a higher chance of them being engaged in corrupt activities in favour of their business contacts (Heywood, 1997). These explanations imply that a person caught between conflicting values for private gain and public responsibility is more likely to become corrupt. This, again, indicates that conflict of interest is one of many causes of corrupt behaviour.

And finally, correlation theories also fall under the reflective explanation category. These theories seek for macroeconomic variables, which have significant correlation with level of corruption in a society. The explanatory variables are not chosen arbitrarily: Huberts relies on panel of experts, who are surveyed to identify most suitable candidates for regressors (Huberts, 1998). The study finds a statistically significant relationship between suggested regressors and corruption level, but the author himself issues a warning: "The presented data are convincing that there exists a relationship between the two variables but it is not clear whether this relationship is of a causal nature." (Huberts, 1998, p. 213) De Graaf fairly points out that very often there is no comprehensive explanation of causal link between explanatory variables and the level of corruption (De Graaf, 2007). We can add that attempting to explain micro-level phenomenon with macro-level variables can lead to false conclusions.

We believe that reflective theories to explain corruption are the product of an attempt to isolate the root of the problem to single determinant. Theories of this type see the factors influencing corrupt behaviour as the sole cause of that wrongdoing. It is obvious that social (external) factors play a key role in making corrupt decisions - however, none of them can be seen as a universal cause of those decisions. Even if a person is ill-educated, or under the influence of a largely corrupted environment, or caught in conflicting interests, or under social pressure for public efficiency, he still can choose to be honest. The sole purpose for us to show theories in reflective and expressive categories is to underline this fundamental logic.

Among theories of causes of corruption, only the public choice approach can be categorized as expressive explanation. It is based on rational choice theory and describes a corrupt person as "rational beings attempting to further their own self-interest in a world of scarce resources" (Rose-Ackerman, 1978, p. 5). Klitgaard suggests a more comprehensive definition stating that a person weighs the net benefit from corrupt activity against net benefits from remaining honest (Klitgaard, 1988). If net benefits from corruption are higher than net benefits from honesty - a person chooses to be corrupt. We can conclude that a person chooses to be 
corrupt simply because he can and external factors influence the existence of corruption indirectly via the prism of an individual's subjective assessment. We now examine how these external factors (or determinants) of corrupt behaviour suggested by different theories influence the decision of an individual.

\section{Determinants of corrupt Behaviour}

We differentiate between contributive determinants and preventive determinants. By contributive we mean the factors that work in favour of the corrupt decision and, similarly, by preventive we mean factors that divert a person from behaving corruptly.

Treisman fairly states, "the most obvious cost is the risk of getting caught and punished" (Treisman, 2000, p. 402). Carson goes further and, as factors of criminal decisions, considers three terms: (1) severity of the punishments for the crime, (2) person's awareness that his actions are illegal and punishable, and (3) probability of the punishments to be imposed (Carson, 2014). Based on these terms, a rational individual builds his expectations about the costs of being involved in corruption.

Severe punishment is very often perceived to be a preventive determinant of corrupt behaviour: if the government imposes harsher penalties for corrupt officials, there would be less incentive to behave corruptly. Although this logic seems very relevant, there is weak empirical evidence in its support. Zhu, in an example of China, shows that even though this country imposes life imprisonment and capital punishment for corrupt officials, there is no statistically proven relationship between severity of penalties and level of corruption (Zhu, 2012). This mismatch between theory and real-life evidence indicates that there are other contributive factors involved.

One of those factors can be lack of awareness of an action to be corrupt: a person may simply be unaware that his actions are illegal. Carson underlines that complexity of the issue and absence of clear definitions of what is legal and what is illegal, makes it difficult for an individual to understand the consequences of his actions (Carson, 2014). Especially, in case of petty corruption, where small amounts of money are involved, a bribee may not realize that this is illegal.

A rational individual also considers the probability of being caught i.e. how likely his wrongdoing is going to be detected. Even if the punishment is severe and a person is aware of it, what if there is very little chance of his crime being detected? Would he still be afraid of punishment? Backer quotes from Lord Shawness: "Certainty of detection is far more important than severity of punishment" (Backer, 1968, p. 9). Although this conclusion seems intuitive, we do not see supporting empirical evidence in its favour.

The probability of being detected is subjectively estimated by an individual (Mehlkop \& Graeff, 2010). A person's estimation of how likely he is going to be caught may depend on many factors: for instance, De Graaf points out that trust in another party can reduce expected risk of being detected (De Graaf, 2007). If the briber is a friend or family member of the bribe-taker, the latter is more confident that he will not be ratted out.

The full estimation of costs of corruption is not complete without one more term: probability of being prosecuted when caught. A corrupt activity of a person can be revealed by authorities - yet, he still can have a chance to escape the punishment for some reason. The estimated cost of a crime increases, when the probability of prosecution approaches $100 \%$. Backer supports this idea:

"Practically all the diverse theories agree, however, that when other variables are held constant, an increase in a person's probability of conviction or punishment if convicted would generally decrease, perhaps substantially, perhaps negligibly, the number of offenses he commits." (Backer, 1968, p. 9)

Probability of prosecution can be less than $100 \%$, if, for example, supervisors of a bribetaking employee caught with corruption are aware of the problem or even involved in corruption; or if authorities responsible for prosecuting detected corruption crimes are corrupt themselves or when "due to legal, political, or policy hurdles, high-level officials may be less likely to be prosecuted or punished for such offenses" (Carson, 2014).

Organizational culture theories are relevant here. If corruption is commonly accepted in an organization, a person would feel safer: he would be aware of many cases when his colleagues escaped prosecution even when caught. Ashforth and Anand provide an example of police office, where people are confident that 
they are going to escape punishment even when caught with corruption (Ashforth \& Anand, 2003).

\section{Necessary Costs of Corruption}

It is also important to understand the difference between expected cost and necessary cost of a bribe. Expected cost of corruption is an estimated damage to a person's own interests, when and if his corrupt behaviour is revealed and punished. Necessary cost is time and efforts a person actually spends to negotiate and conduct corrupt activity and manage its consequences. Carson (2014) provides a very comprehensive description of necessary costs:

While all forms of corruption generate some transaction costs such as the time and resources devoted to planning, pursuing, and concealing the scheme, corrupt transactions ... create additional costs as participants must identify and negotiate with partners, monitor the progress of coconspirators, and enforce corrupt agreements. Opportunity costs refer to the value of the time that the actor will spend engaging in and hiding illegal activities - as well as defending against any charges if discovered - which could otherwise be dedicated to lawful employment or other pursuits. (Carson, 2014, p. 16)

After the review of previous studies on the topic of corruption, we conclude that this phenomenon can be further analysed within the frame of rational choice theory. We believe that the present paper would be a good contribution to corruption studies. The model proposed below potentially can serve as policy assessment tool for anti-corruption initiatives.

\section{RATIONAL CHOICE THEORY OF CORRUPT DECISION}

Rational decision-making is modelled by a combination of a utility function, which is subjective wellbeing of a person from consuming a bundle of $n$ or more goods, and a budget constraint, which represents the ability a person has to acquire these goods due to his endowments.

We apply the same logic to the case of corruption. We define income (dollars) as utility-giving 'goods'. When a person receives dollars, his utility is at a certain level. When the amount of dollars he is obtaining increases, his utility also rises.
We divide income into two types: corrupt income $(\operatorname{good} x)$ and honest income (good $y$ ). Although, in theory an individual can choose any combination of these two types of income, his choices are bounded by constraints. He has to spend a certain amount of time to obtain each corrupt dollar (price of good $x$ ) and each honest dollar (price of good $y$ ). However, he has limited time which he can spend on earning income. Consequently, depending on the amount of corrupt and honest dollars he wishes to obtain, he has to allocate his time endowment between obtaining corrupt and honest dollars. As our goods are dollars and they are perfect substitutes, we conclude that utility is maximized when the total amount of obtained dollars is maximized.

Based in the above we can formulate assumptions for our model:

Assumption 1: Corruption is rational choice phenomenon. This assumption is based on the definition we chose to work with. It limits the study of corruption in this paper to economic factors influencing the corrupt behaviour.

Assumption 2: Any corrupt activity has direct financial benefit. We assume that an individual decides to receive bribe only when he has direct financial gain from it.

Assumption 3: An individual's moral distinction between an honest and a corrupt dollar is linear. Here we assume that a corrupt dollar gives the same or proportionately less level of utility as an honest dollar. By 'linear' we mean that an increase in corrupt income does not change moral burden. For instance, if a person's utility is decreased by $50 \%$ (due to moral distress from being engaged in wrongdoing) when a dollar is corrupt compared to honest dollar, then each 2 dollars from corrupt activities will give the same utility as each honest dollar. This assumption is justified in our case, as we are dealing with petty corruption where bribe involves lesser amounts of money.

Assumption 4: A rational person is riskneutral. Here we assume that necessary costs of corruption for an individual are equal to expected costs, i.e. he is ready to spend the same amount of time on conducting and hiding corruption as he expects to lose if caught and punished. A risk-averse person would spend more time on hiding the crime then necessary and a risk-lover would spend less time than necessary to avoid expected 
costs.

Assumptions suggest that we focus solely on the economic dimension, ignoring socialcultural and psychological factors of corrupt behaviour. Where possible, social factors are quantified in the form of probabilities. This raises reasonable questions about the reliability of the proposed model, as due to this limitation, we may fail to explain the cases where noneconomic factors prevail.

\section{PROPOSED MODEL}

\section{Components of the Model}

With assumptions in mind, we can develop a model. We start with a basic utility function to represent tastes of a corrupt person. A person is choosing between consuming honest dollars $(H)$ and corrupt dollars $(C)$. Assumption 3 indicates that for him these are perfect substitutes. Mathematically it can be expressed as follows:

$$
\begin{aligned}
U= & m C+H \\
& 0 \leq m \leq 1
\end{aligned}
$$

where $U-$ is total utility level of an individual from combined consumption of honest and corrupt income; $C$ - is total monthly corrupt income, $H$ - is total monthly honest income, and $m$ - is moral tolerance factor. If $m$ is equal to 0 (zero tolerance to corruption), then a person is completely honest. Similarly, if $m$ is 1 , a person is completely indifferent between honest and corrupt income.

As to the budget constraint, we introduce an approach of using time as a unit of cost. A person has a limited monthly time endowment and decides on how to distribute this time between honest work hours and time spent on conducting and handling corruption. Hence, our time constraint function looks like the following:

$$
\begin{gathered}
t=t_{c} C+t_{h} H \\
\text { or } \\
t=p d a\left(s+\frac{1}{w}\right) C+\left(\frac{t}{w t+c}\right) H
\end{gathered}
$$

where $t$ - is total monthly time endowment (in hours) of an individual available for income earning, $p d a\left(s+\frac{1}{w}\right)$ - is time-cost of securing each corrupt dollar (it is important to understand that obtaining corrupt dollars does not have any time-cost, as a person is getting a bribe while doing his everyday tasks). Real time-cost of each corrupt dollar is equal to severity of punishment $s$ (direct cost) plus official hourly earning $\frac{1}{w}$ (opportunity cost). This actual cost goes through the prism of person's expectations: awareness of punishment $a$, probability of detection $d$, and probability of prosecution $p$.

The term $\frac{t}{w t+c}$ - is time-cost of earning each honest dollar. Time-cost of each honest dollar is total time endowment divided by the sum of hourly official earning and hourly corrupt earning: we can see here that relative time-cost of honest dollar decreases when corrupt income is present.

\section{Demand for Corruption}

Maximizing utility function 4.1 subject to time constraint 4.2 gives us the following demand for corruption function (all steps of derivation are shown in Appendix A):

$$
\begin{gathered}
C=\frac{w t}{2}\left(\frac{1+m}{p d a(s w+1)}-1\right) \\
m>0
\end{gathered}
$$

We attach the condition that $m$ must be greater than 0 , as $m=0$ means a person is completely honest and his utility is independent from the amount of corrupt income.

\section{Extreme Cases}

We now review the cases when of the probabilities are equal to zero. Here we assume that a person is completely unaware that corruption is a punishable crime (i.e. $a$ is zero), or a crime has all chances to remain undetected (i.e. $d$ is zero), or a person has all chances to escape prosecution for his crime (i.e. $p$ is zero).

Setting any of these terms equal to zero brings the demand function to the following form:

$$
\begin{gathered}
C=\frac{w t}{2}\left(\frac{1+m}{p d a(s w+1)}-1\right) \\
\lim _{p d a \rightarrow 0} C=\infty
\end{gathered}
$$

The above function indicates that when any probability is equal to zero, a person is ready to accept unlimited amount of corrupt income i.e. demand for corruption rises infinitely.

Another extreme case is the full probabilities case. Here we assume that all probability terms $(a, d, p)$ are equal to 1 . In this case, our demand for corruption function becomes:

$$
c=\frac{w t}{2}\left(\frac{1+m}{s w+1}-1\right)
$$

In the above function, the direct cost of each corrupt dollar fully translates into necessary 
cost. Demand for corruption is inversely related to punishment severity level and official wage rate.

\section{POLICY IMPLICATIONS}

Any anti-corruption policy, ideally, aims at eliminating corruption. Speaking in terms of our proposed model, our goal is to create an environment where demand for corruption is zero:

$$
\begin{gathered}
c \leq 0 \\
\frac{w t}{2}\left(\frac{1+m}{p d a(s w+1)}-1\right) \leq 0
\end{gathered}
$$

We can achieve this by setting one of the multipliers equal to zero. We exclude cases when $t=0$ i.e. a person does not spend any time on income earning and where $w=0$ i.e. a person is doing free volunteer work for the public. So, we end up with:

$$
p d a(s w+1) \geq 1+m
$$

which is the condition for zero demand for corruption. The inequality 5.1 shows that anticorruption policies should target increasing the probability terms $p, d$, and $a$ and/or raising $s$ or $w$. Raising the punishment severity or the official wage rate we call direct policies, and targeting probability terms - indirect policies.

\section{Direct Policies}

The state may consider using discriminative punishment levels for diverse groups of officials. For example, as previous studies repeatedly stated, law enforcement officers have higher level of awareness, and they also have lower probability of being prosecuted. To compensate for this lower probability of being prosecuted, governments might set harsher punishment levels for officials of this type. With similar logic, Interpol sets out as one of its principles to combat corruption in police forces, as "to make corruption within police forces/services a highrisk crime" (Interpol, 2002, p. 6).

Van Rijckeghem and Weder suggested empirical evidence that raising wages for public employees reduces corruption. Based on crosscountry data on 31 nations they concluded that increasing relative wages in public sector, in the long-run, reduces petty corruption (Van Rijckeghem \& Weder, 2001).

\section{Indirect Policies}

The level of awareness about the illegality of and punishment for corruption is directly related to the quality of legal (or civil) education provided to public employees. Thus, the only way of raising the awareness is to provide better training for the staff of government organizations.

Simpler procedures at public offices ensures high probability of spotting deviations. This approach is based on the power of public control, where society, if given proper conditions, can self-regulate the integrity of public officials.

Monitoring and auditing are also advocated to have preventive effects on corruption by increasing the probability of being detected. However, as Spengler rephrases Becker's model of crime, raising the probability of detection can be very costly for the government because it requires hiring more inspectors (Spengler, 2014). This also might create the problem of integrity of monitors/auditors themselves: as any economic agent, inspectors can also be corrupted.

The probability of prosecution is the most difficult term for the government to influence. It requires large-scale social reforms to ensure rule of law. In this regard, independence of the judicial branch of power is essential. Law enforcement should be able to prosecute any revealed corrupt behaviour without fear of consequences from political forces. This ensures that the probability of being prosecuted for corruption is not distorted by 'good connections' an offender may have with political figures and/or the criminal-justice system.

\section{CONCLUSION}

In this paper, we have used rational choice theory to understand and model the behaviour of an individual in case of corruption. We showed that corruption is becoming an increasingly complex issue and we suggested a definition of corruption on which we based our analysis.

Reviewed theoretical literature suggested that corrupt behaviour is a choice of a rational person to be corrupt - a choice which is the result of many contributing and preventing factors. Distinguishing between contributive and preventive factors enabled us to come up with the set of assumptions to build a new model of corrupt behaviour.

Based on the proposed model, we made 
several suggestions on implementing better anti-corruption policies. Namely, we argued that corruption cannot be eliminated only by raising the wages of public officials or by imposing harsher penalties for corrupt behaviour. With the help of the model, we showed that awareness level, perceived probabilities of being caught and punished should also be addressed.

Further improvement of the model would be inclusion of social/environmental factors such as political will to fight corruption and cultural attitudes towards corruption. Moreover, the proposed model should be put to the test with cross-country empirical data: empirical validation would allow one to identify and mitigate weaknesses in the model and to improve relevance of policy suggestions based on it.

In its simple formulation, the article attempted to answer the question 'Why do people take bribes?' To complete the picture of corrupt behaviour, the next logical step in this regard would be to answer the question 'Why do people give bribes?' This would enable us to better understand the 'supply' side of the issue. And finally, we would be able to bring demand and supply together and observe their interaction. This is a clear direction to continue and extend the research of corruption.

We are always in the beginning of knowing something better.

\section{REFERENCE}

Ashforth, B., \& Anand, V. (2003). The

Normalization Of Corruption In Organizations. Research in Organizational Behavior, 25, pp.1-52.

Backer, G. (1968). Crime and Punishment: An Economic Approach. Journal of Political Economy, 78, pp.169-217.

Carson, L. D. (2014, November 6). Deterring Corruption: Beyond Rational Choice Theory. Retrieved February 12, 2017, from SSRN: https://ssrn.com/abstract $=2520280$

De Graaf, G. (2007). Causes Of Corruption: Towards A Contextual Theory Of Corruption. Public Administration Quarterly, 31(1), 3986. Retrieved February 21, 2017, from http://www.jstor.org/stable/41288282

Gardiner, J. (2009). Defining Corruption. In A. J. Heidenheimer, \& M. Johnston (Eds.), Political Corruption: Concepts and Contexts (3rd ed., pp. 25-40). New Brunswick, New Jersey: Transaction Publishers.

Heywood, P. (1997). Political Corruption Problems and Perspectives. Political Studies, 45(3), pp. 417-435.

Huberts, L. (1998). What can be done against public corruption and fraud: Expert views on strategies to protect public integrity. Crime, Law and Social Change, 2(3), pp. 209-224.

Interpol. (2002). Global Standards to Combat Corruption In Police Forces/Services. Interpol. Retrieved October 27, 2017, from https://www.interpol.int/Media/Files/Crime -areas/Corruption/Global-standards-tocombat-corruption-in-police-forces

Klitgaard, R. (1988). Controlling Corruption. University of California Press.

Mehlkop, G., \& Graeff, P. (2010). Modelling a rational choice theory of criminal action: Subjective expected utilities, norms, and interactions. Rationality and Society, 2(22), pp. 189-222.

Nas, T. F., Price, A. C., \& Weber, C. T. (1986). A Policy-Oriented Theory of Corruption. The American Political Science Review, 801), 107-119. Retrieved February 11, 2017, from http://www.jstor.org/stable/1957086

Ndongmo, C. (2014). The Economics of Corruption: A Study of its rationale and measures. University of York. Retrieved September 15, 2017, from http://etheses.whiterose.ac.uk/10779/

Punch, M. (2000). Police Corruption and its Prevention. European Journal on Criminal Policy and Research301-324, 8(3), pp. 301324.

Rose-Ackerman, S. (1978, na na). Corruption: A Study in Political Economy. New York: Academic Press Inc. Retrieved from Peterson Institute for International Economics.

Spengler, D. E. (2014, September). Detection and Deterrence in the Economics of Corruption: a Game Theoretic Analysis and some Experimental Evidence. University of York. Retrieved from http://etheses.whiterose.ac.uk/7828/1/DES\% 20Thesis\%202nd\%20submission.pdf

Svensson, J. (2015). Eight Questions about Corruption. Journal of Economic Perspectives, 19(3), pp. 19-42. 
Treisman, D. (2000). The causes of corruption: a cross-national study. Journal of Public Economics, 76(3), pp. 399-457.

Van Rijckeghem, C., \& Weder, B. (2001). Bureaucratic corruption and the rate of temptation: do wages in the civil service affect corruption, and by how much? Journal of Development Economics, 65, pp. 307-331.

Zhu, J. (2012). Do Severe Penalties Deter Corruption? A Game-Theoretic Analysis of the Chinese Case. China Review, 12(2), 1-32. Retrieved February 12, 2017, from http://www.jstor.org/stable/23462215

\section{ABOUT THE AUTHOR}

Javlon Juraev: javjur@nupi.no

Mr. Javlon Juraev (Uzbekistan) is a visiting research fellow at Norwegian Institute of International Affairs (NUPI). He holds MA in Economic Governance and Development from the OSCE Academy and BSc in Economics from the University of Westminster. 
Appendix A. Derivation of demand for corruption function

First, we rewrite utility and time-constraint functions:

$$
\begin{gathered}
U=m C+H \\
t=p d a\left(s+\frac{1}{w}\right) C+\left(\frac{t}{w t+C}\right) H
\end{gathered}
$$

Setting up Lagrange gives us:

$$
L=m C+H+\lambda\left(t-p d a\left(s+\frac{1}{w}\right) C-\left(\frac{t}{w t+C}\right) H\right)
$$

First order conditions:

$$
\begin{gathered}
\frac{d L}{d C}=m+\lambda\left(\left(\frac{t}{(w t+C)^{2}}\right) H-p d a\left(s+\frac{1}{w}\right)\right)=0 \\
\frac{d L}{d H}=1+\lambda\left(-\frac{t}{w t+C}\right)=0 \\
\frac{d L}{d \lambda}=t-\left(\frac{t}{w t+C}\right) H-p d a\left(s+\frac{1}{w}\right) C=0
\end{gathered}
$$

Rearranging and dividing first two:

Solving for $h$ :

$$
\frac{m}{1}=\frac{\lambda\left(p d a\left(s+\frac{1}{w}\right)-\left(\frac{t}{(w t+C)^{2}}\right) H\right)}{\lambda\left(\frac{t}{w t+C}\right)}
$$

$$
\begin{gathered}
m=\frac{p d a\left(s+\frac{1}{w}\right)-\left(\frac{t}{(w t+C)^{2}}\right) H}{\frac{t}{w t+C}} \\
m\left(\frac{t}{w t+C}\right)=p d a\left(s+\frac{1}{w}\right)-\left(\frac{t}{(w t+C)^{2}}\right) H \\
m t(w t+C)=p d a\left(s+\frac{1}{w}\right)(w t+C)^{2}-t H \\
t H=p d a\left(s+\frac{1}{w}\right)(w t+C)^{2}-m t(w t+C) \\
H=\frac{p d a\left(s+\frac{1}{w}\right)(w t+C)^{2}}{t}-m(w t+C)
\end{gathered}
$$

Plugging this into time-constraint function, we get:

$$
\begin{gathered}
t=\frac{t}{w t+C}\left(\frac{p d a\left(s+\frac{1}{w}\right)(w t+C)^{2}}{t}-m(w t+C)\right) \\
+p d a\left(s+\frac{1}{w}\right) C
\end{gathered}
$$

And we solve for $c$.

$$
\begin{gathered}
t=p d a\left(s+\frac{1}{w}\right)(w t+C)-m t+p d a\left(s+\frac{1}{w}\right) C \\
t(1+m)=p d a\left(s+\frac{1}{w}\right)(w t+C+C) \\
\frac{t(1+m)}{p d a\left(s+\frac{1}{w}\right)}=w t+2 C \\
C=\frac{t(1+m)}{2\left(\frac{p d a(s w+1)}{w}\right)}-\frac{w t}{2}
\end{gathered}
$$

Final rearrangement gives us:

$$
C=\frac{w t(1+m)}{2 p d a(s w+1)}-\frac{w t}{2}
$$

or

$$
C=\frac{w t}{2}\left(\frac{1+m}{p d a(s w+1)}-1\right)
$$

which is our demand for corruption function. 